Int Surg 2015;100:1004-1010

DOI: 10.9738/INTSURG-D-14-00240.1

\title{
Delayed Appendectomy Is Safe in Patients With Acute Nonperforated Appendicitis
}

\author{
Sang Hyun Kim ${ }^{1}$, Sun Jin Park ${ }^{2}$, Youn Young Park ${ }^{1}$, Sung Il Choi ${ }^{1}$ \\ ${ }^{1}$ Department of Surgery, Kyung Hee University School of Medicine, Kyung Hee University Hospital at \\ Gangdong, Gangdong-gu, Seoul, Korea \\ ${ }^{2}$ Kyung Hee University Hospital, Seoul, Korea
}

The present study examined whether acute, nonperforated appendicitis is a surgical emergency requiring immediate intervention or a disease that can be treated with a semielective operation. Immediate appendectomy has been the gold standard in the treatment of acute appendicitis because of the risk of pathologic progression. However, this time-honored practice has been recently challenged by studies suggesting that appendectomies can be elective in some cases and still result in positive outcomes. This was a retrospective study using the charts of patients who underwent an appendectomy for acute, nonperforated appendicitis between January 2007 and February 2012. Patients were divided into 2 groups for comparison: an immediate group (those who were moved to an operating room within 12 hours after hospital arrival) and a delayed group (those within 12 to 24 hours after hospital arrival). The end points were conversion rate, operative time, perforation rate, complication rate, readmission rate, length of hospital stay, and medical costs. Of 1805 patients, 1342 (74.3\%) underwent immediate operation within 12 hours after hospital arrival, whereas $463(25.7 \%)$ underwent delayed operation within 12 to 24 hours. There were no significant differences in open conversion, operative time, perforation, postoperative complications, and readmission between the 2 groups. Length of hospital stay was significantly greater ( $3.7 \pm 1.7$ days) and medical costs were also greater [ $\$ 2346.30 \pm \$ 735.30$ (US dollars)] in the delayed group than in the immediate group [3.1 \pm 1.9 days; $P=0.000$ and $\$ 2257.80 \pm \$ 723.80$ (US dollars); $P=0.026]$. Delayed appendectomy is safe for patients with acute nonperforated appendicitis.

Key words: Delayed appendectomy - Immediate appendectomy - Nonperforated appendicitis

Corresponding author: Sung Il Choi, 134-727, Department of Surgery, Kyung Hee University Hospital at Gangdong, 892, Dongnamro, Gangdong-gu, Seoul, Korea.

Tel.: +82 103397 4165; Fax: +82 2440 6295; E-mail: drchoi@khu.ac.kr 
$\mathrm{A}$ cute appendicitis is one of the most common acute diseases requiring an emergency operation. Immediate appendectomy is considered the gold-standard treatment for acute appendicitis. It is widely believed that delays in diagnosis and treatment significantly contribute to increased incidences of perforated appendicitis, which result in increased patient morbidity. ${ }^{1}$ Nevertheless, in some cases, the appropriate operation has been delayed because of reasons such as lack of fasting time for general anesthesia, unavailability of operating rooms, and overscheduling of operating teams. Recently, some studies have challenged the impact of these delays and standard of care with appendectomy by suggesting that acute appendicitis can either be treated medically ${ }^{2,3}$ or operated on electively without increasing morbidity. ${ }^{4-7}$ Given these considerations, we used electronic medical records to review 1805 cases of appendectomy for acute appendicitis between January 2007 and February 2012 to verify whether acute nonperforated appendicitis necessitates immediate intervention or can be treated with a semielective operation.

\section{Methods}

\section{Patients}

A retrospective review of the charts of all patients who underwent an appendectomy for acute appendicitis at Kyung Hee University Hospital at Gangdong from January 2007 to February 2012 was performed. Diagnosis of acute nonperforated appendicitis was based on a doctor's decision after considering clinical manifestation, physical examination, laboratory findings, and radiologic modalities. Patients who were preoperatively diagnosed with perforated appendicitis, underwent interval appendectomy or negative appendectomy, or underwent an operation after consulting with other departments were excluded from analysis. Antibiotics such as cephalosporin were administered as soon as possible after diagnosis and were continued until patient discharge. The data for the following parameters were gathered from electronic medical records: demographic characteristics (age, sex), body mass index (BMI), American Society of Anesthesiologists (ASA) score, white blood cell (WBC) count at admission, body temperature at admission, time from onset of symptoms to hospital arrival (patient interval), time from hospital arrival to the operating room (hospital interval), radiologic findings according to diagnostic modalities, methods of surgery, operative time, and final pathology. The patients were divided into 2 comparison groups: immediate group (those with a hospital interval $\leq 12$ hours) and delayed group (those with a hospital interval from 12 to 24 hours). The end points chosen for comparison were safety-related outcomes: laparoscopic to open conversion rate, operative time, perforation rate, complication rate, and readmission rate; economy-related outcomes: length of hospital stay and medical cost; and accuracy of diagnostic modalities for distinguishing the difference between nonperforated and perforated appendicitis. This study was approved by the Institutional Review Board at Kyung Hee University Hospital at Gangdong (KHNMC 201411-011).

\section{Statistical analysis}

Demographic and clinical characteristics were summarized as means (for continuous variables) or proportions (for categoric variables) and compared using $t$-tests or $\chi^{2}$ tests, respectively. A $P$ value of less than 0.05 was considered statistically significant. All statistical analyses were performed using Statistical Package for Social Sciences (SPSS) software version 18.03 (SPSS Inc, Chicago, Illinois).

\section{Results}

\section{Patient demographics}

During the 5-year study period, 2093 patients underwent appendectomy for acute appendicitis. Of the 2093 patients, 288 patients were excluded from analysis because of perforated appendicitis in preoperative diagnosis, interval appendectomy, negative appendectomy, and operation after consultation from other departments. Among the 1805 patients included for analysis, 1342 (74.3\%) underwent an appendectomy within 12 hours after hospital arrival (immediate group) and 463 (25.7\%) underwent an appendectomy from 12 to 24 hours after hospital arrival (delayed group). No patient underwent surgery more than 24 hours after hospital arrival. Patients were on average $31.7 \pm$ 17.9 years old and predominantly male $(1014 / 1805$, $56.2 \%)$. On average, BMI $\left(\mathrm{kg} / \mathrm{m}^{2}\right)$ was $22.2 \pm 3.9$, patient interval was $27.7 \pm 36.4$ hours, and WBC counts $\left(10^{3} / \mathrm{dL}\right)$ were $13.0 \pm 4.5$. No significant differences in age, sex, BMI, ASA score, patient interval, or WBC count were noted between the 2 groups. Body temperature was significantly differ- 
Table 1 Patient characteristics

\begin{tabular}{|c|c|c|c|}
\hline Variables & Immediate $(\mathrm{n}=1342)$ & Delayed $(n=463)$ & $P$ value \\
\hline Age (years $\pm S D)$ & $31.4 \pm 18.2$ & $32.8 \pm 16.9$ & 0.144 \\
\hline Sex & & & 0.440 \\
\hline Male & 761 (56.7) & $253(54.6)$ & \\
\hline Female & $581(43.3)$ & $210(45.4)$ & \\
\hline $\operatorname{BMI}\left(\mathrm{kg} / \mathrm{m}^{2}\right)$ & $22.1 \pm 4.1$ & $22.5 \pm 4.1$ & 0.074 \\
\hline ASA score & & & 0.329 \\
\hline 1 & $355(27.3)$ & $114(25.1)$ & \\
\hline 2 & $922(70.9)$ & $331(72.9)$ & \\
\hline 3 & $18(1.4)$ & $7(1.5)$ & \\
\hline 4 & $2(0.2)$ & $0(0)$ & \\
\hline 5 & $2(0.2)$ & $2(0.4)$ & \\
\hline Patient interval ${ }^{\mathrm{a}}$ (hours) & $27.8 \pm 33.4$ & $27.2 \pm 44.2$ & 0.737 \\
\hline WBC $\left(10^{3} / \mathrm{dL}\right)$ & $13.1 \pm 4.6$ & $12.9 \pm 4.2$ & 0.495 \\
\hline Body temperature $\left({ }^{\circ} \mathrm{C}\right)$ & $36.6 \pm 0.6$ & $36.7 \pm 0.5$ & 0.001 \\
\hline
\end{tabular}

Values are presented as number (\%) unless otherwise indicated.

ASA, American Society of Anesthesiologists; BMI, body mass index; ${ }^{\circ} \mathrm{C}$, centigrade; $\mathrm{dL}$, deciliter; SD, standard deviation; WBC, white blood cell.

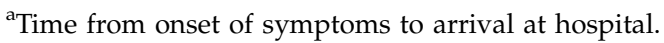

ent between the immediate group $\left(36.6 \pm 0.6^{\circ} \mathrm{C}\right)$ and delayed group $\left(36.7 \pm 0.5^{\circ} \mathrm{C} ; P=0.001\right)$, but was considered clinically nonsignificant because body temperatures in both groups were within the normal range (Table 1).

\section{Safety-related outcomes}

There were no significant differences in the laparoscopic to open conversion rate $(0.5 \%$ in the immediate group and $0.2 \%$ in the delayed group), operative time $(45.8 \pm 21.4$ minutes in the immediate group and $46.0 \pm 23.6$ minutes in the delayed group), perforation rate based on final pathology
(12.8\% in the immediate group and $12.1 \%$ in the delayed group), postoperative complication rate $(6.0 \%$ in the immediate group and $6.0 \%$ in the delayed group), and readmission rate $(2.5 \%$ in the immediate group and $2.2 \%$ in the delayed group) between the 2 groups (Table 2).

\section{Economy-related outcomes}

Overall length of hospital stay was significantly greater in the delayed group ( $3.7 \pm 1.7$ days) than in the immediate group ( $3.1 \pm 1.9$ days; $P=0.000)$. The difference in length of postoperative hospital stay, however, was nonsignificant between the 2 groups

Table 2 Safety-related outcomes

\begin{tabular}{|c|c|c|c|}
\hline Variables & Immediate $(n=1342)$ & Delayed $(n=463)$ & $P$ value \\
\hline \multicolumn{4}{|l|}{ Operative procedure } \\
\hline Laparoscopy & $1266(94.3)$ & $443(95.7)$ & 0.267 \\
\hline Open & $62(4.6)$ & $16(3.5)$ & 0.288 \\
\hline Open conversion & $7(0.5)$ & $1(0.2)$ & 0.393 \\
\hline Cecectomy & $7(0.5)$ & $3(0.6)$ & 0.752 \\
\hline Operative time (minute) & $45.8 \pm 21.4$ & $46.0 \pm 23.6$ & 0.833 \\
\hline Postoperative diagnosis & & & 0.687 \\
\hline Simple & $1170(87.2)$ & 407 (87.9) & \\
\hline Perforated & $172(12.8)$ & $56(12.1)$ & \\
\hline \multicolumn{4}{|l|}{ Complications } \\
\hline All & $80(6.0)$ & $28(6.0)$ & 0.946 \\
\hline Wound infection & $54(4.0)$ & $18(3.9)$ & 0.897 \\
\hline Intraabdominal infection & $23(1.7)$ & $7(1.5)$ & 0.769 \\
\hline Other $^{\mathrm{a}}$ & $3(0.2)$ & $3(0.6)$ & 0.180 \\
\hline Readmissions & $33(2.5)$ & $10(2.2)$ & 0.716 \\
\hline
\end{tabular}

Values are presented as number (\%) unless otherwise indicated.

ammediate; ileus (3) delayed; obstruction (2), mesenteric lymphadenitis (1). 
Table 3 Economy-related outcomes

\begin{tabular}{lccc}
\hline Variables & Immediate $(\mathrm{n}=1342)$ & Delayed $(\mathrm{n}=463)$ & $P$ value \\
\hline LHS $^{\mathrm{a}}$ (days) & $3.1 \pm 1.9$ & $3.7 \pm 1.7$ & 0.000 \\
Postoperative LHS (days) & $3.0 \pm 1.8$ & $2.9 \pm 1.6$ & 0.622 \\
Cost (US dollars) & $2257.8 \pm 723.8$ & $2346.3 \pm 735.3$ & 0.000 \\
\hline
\end{tabular}

${ }^{\mathrm{a}}$ LHS, Length of hospital stay.

$(3.0 \pm 1.8$ days in the immediate group and $2.9 \pm$ 1.6 days in the delayed group; Table 3). Total medical cost was $\$ 2346.30 \pm \$ 735.30$ US dollars in the delayed group, slightly greater than the $\$ 2257.80$ $\pm \$ 723.80$ US dollars in the immediate group ( $P=$ $0.000)$.

\section{Accuracy of radiologic modalities}

The sensitivity of computed tomography (CT; probability of patients diagnosed with nonperforated appendicitis by CT among those diagnosed with nonperforated appendicitis by pathology) was $97.0 \%(879 / 906)$ and specificity of CT (probability of patients diagnosed with perforated appendicitis by CT among those diagnosed with perforated appendicitis by pathology) was $46.1 \%$ $(125 / 271)$ in our data (Table 4). The false-positive rate of CT (probability of patients diagnosed with nonperforated appendicitis by CT among those diagnosed with perforated appendicitis by pathology) was as high as $53.9 \%(146 / 271)$. The sensitivity of ultrasonography (US) was $95.5 \%(530 / 555)$ and specificity of US was $38.9 \%(37 / 95)$ in our records (Table 5). The false-positive rate of US (probability of patients diagnosed with nonperforated appendicitis by US among those diagnosed with perforated appendicitis by pathology) was as high as $61.1 \%(58 / 95)$.

\section{Discussion}

The present study demonstrated that semielective appendectomies for patients with acute nonperforated appendicitis do not increase the morbidity (defined as open conversion rate, operative time, perforation rate, postoperative complication rate, and readmission rate) but do increase economic factors such as medical costs and length of hospital stay.

Our findings were consistent with those of several other studies that have not found increased rates of complications among patients with delayed appendectomy. In a study of 380 patients with acute appendicitis, Abou-Nukta et $a l^{5}$ demonstrated that an appendectomy delay of greater than 12 hours

Table 4 Accuracy of computed tomography

\begin{tabular}{|c|c|c|c|c|}
\hline Variables & Nonperforated in pathology & Perforated in pathology & All & \\
\hline Nonperforated on CT & $\begin{array}{l}879 \\
97.0 \%{ }^{\mathrm{a}}\end{array}$ & $\begin{array}{l}146 \\
53.9 \%^{\mathrm{c}}\end{array}$ & 1025 & $85.8 \%^{\mathrm{e}}(879 / 1025)$ \\
\hline Perforated on CT & $\begin{array}{l}27 \\
3.0 \% \mathrm{~b}\end{array}$ & $\begin{array}{l}125 \\
46.1 \%^{\mathrm{d}}\end{array}$ & 152 & $82.2 \%^{\mathrm{f}}(125 / 152)$ \\
\hline All & 906 & 271 & 1117 & \\
\hline
\end{tabular}

Values are presented as number unless otherwise indicated.

CT, computed tomography.

${ }^{a}$ Sensitivity; probability of patients diagnosed with nonperforated appendicitis by CT among those diagnosed with nonperforated appendicitis by pathology.

${ }^{\mathrm{b}}$ False negative rate; 1 -sensitivity.

${ }^{\mathrm{c}}$ False positive rate; 1 -specificity.

${ }^{\mathrm{d}}$ Specificity; probability of patients diagnosed with perforated appendicitis by CT among those diagnosed with perforated appendicitis by pathology.

ePositive predictive value; probability of patients diagnosed with nonperforated appendicitis by pathology among those diagnosed with nonperforated appendicitis by CT.

${ }^{\mathrm{f}}$ Negative predictive value; probability of patients diagnosed with perforated appendicitis by pathology among those diagnosed with perforated appendicitis by $\mathrm{CT}$. 
Table 5 Accuracy of ultrasonography

\begin{tabular}{|c|c|c|c|c|}
\hline Variables & Nonperforated in pathology & Perforated in pathology & All & \\
\hline Nonperforated on US & $\begin{array}{l}530 \\
95.5 \%{ }^{\mathrm{a}}\end{array}$ & $\begin{array}{l}58 \\
61.1 \%^{\mathrm{c}}\end{array}$ & 588 & $90.1 \%{ }^{\mathrm{e}}(530 / 588)$ \\
\hline Perforated on US & $\begin{array}{l}25 \\
4.5 \% \mathrm{~b}\end{array}$ & $\begin{array}{l}37 \\
38.9 \%{ }^{\mathrm{d}}\end{array}$ & 62 & $59.7 \%{ }^{\mathrm{f}}(37 / 62)$ \\
\hline All & 555 & 95 & 650 & \\
\hline
\end{tabular}

Values are presented as numbers unless otherwise indicated.

US, ultrasonography.

aSensitivity; probability of patients diagnosed with nonperforated appendicitis by US among those diagnosed with nonperforated appendicitis by pathology.

${ }^{\mathrm{b}}$ False negative rate; 1 -sensitivity.

${ }^{\mathrm{c}}$ False positive rate; 1 -specificity.

${ }^{\mathrm{d}}$ Specificity; probability of patients diagnosed with perforated appendicitis by US among those diagnosed with perforated appendicitis by pathology.

ePositive predictive value; probability of patients diagnosed with nonperforated appendicitis by pathology among those diagnosed with nonperforated appendicitis by US.

${ }^{\mathrm{f}}$ Negative predictive value; probability of patients diagnosed with perforated appendicitis by pathology among those diagnosed with perforated appendicitis by US.

showed no significant increase in perforation rates, operative time, or length of hospital stay. In addition, Omundsen and Dennett ${ }^{8}$ found that there were no differences in complication rates or length of postoperative hospital stay between patients who underwent appendectomy within 12 hours and from 12 to 24 hours after admission. Omundsen and Dennett's study of 345 appendectomies only showed an increase in morbidity when appendectomy was delayed more than 24 hours. Surana et $a l^{6}$ reported no difference in complication rates between patients undergoing appendectomy within 6 hours compared to 6 to 18 hours after admission in a study of 695 children with appendicitis. In a similar study of 126 pediatric patients with acute nonperforated appendicitis, Yardeni et $_{\text {al }}{ }^{7}$ demonstrated that there were no significant increases in the complication rates or perforation rates when appendectomies were performed within 6,6 to 12 , or more than 12 hours after admission. In a populationbased study that used a database of 32,782 patients and was the largest study supporting this semielective approach, Ingraham $e^{2} \mathrm{al}^{4}$ found that a delay in appendectomy was not associated with increased 30-day morbidity.

In contrast to these studies, several others continue to support the current standard of appendectomy as a standard emergency procedure. In 1081 adult patients with acute appendicitis, Ditillo et $a l^{9}$ found that the risk of developing advanced pathology and complications increased with time until appropriate treatments, suggesting that a delay in appendectomy was unsafe. Udgiri et $a l^{10}$ reported that the complication rates, lengths of hospital stay, and readmissions were greater in a delayed appendectomy group (performed more than 10 hours after admission) than in an immediate appendectomy group (performed less than 10 hours after admission) in a study of 211 patients with appendicitis. Recently, Teixeira et $a l^{11}$ showed that while an appendectomy delay of more than 6 hours did not increase the risk of perforation, it significantly increased the risk of surgical site infection in 4529 patients with nonperforated appendicitis. In contrast, the present study showed no difference in surgical site infection rate, which was approximately $5 \%$ in each group.

The safety of delayed appendectomy can be explained by the development of medical technologies, particularly the injection of antibiotics to halt the progression of appendicitis. A number of studies have shown the effectiveness of antibiotics in treating perforated appendicitis. ${ }^{12-14}$ In most cases, antibiotic administration leads to resolution of the infectious and inflammatory processes of perforated appendicitis, which allows elective appendectomy to be performed 6 to 8 weeks after the initial presentation of disease. Moreover, 2 randomized controlled trials suggested that acute appendicitis could be successfully treated with antibiotics and that antibiotics might be a first-line therapy in acute appendicitis. ${ }^{2,3}$

Among a total of 1805 cases, we performed 190 appendectomies (10.5\%) for acute appendicitis between the hours of $11 \mathrm{PM}$ and 8 AM. When a patient was diagnosed with nonperforated appen- 
dicitis at these hours, we often had no choice but to delay an operation, offer antibiotic therapy, and schedule an operation for the following day. The unavailability of an emergency operating room or operating team members such as an anesthesiologist, nurse, or assistant prohibited prompt operation. The results of this report may lessen surgeons' stress in this situation, as the increasing risk of perforation and subsequent morbidity in appendicitis progression may be less significant than previously thought. This optimistic finding could have a positive psychologic effect on surgeons, resulting in a more meticulous operation the following day with enhanced care for patients. In addition, the current government policy that surgical specialists should care for their patients in the emergency room greatly increases the responsibility of surgeons. Our findings suggest that surgeons could delay operations for less critically ill patients, such as those with nonperforated appendicitis, in order to appropriately care for those requiring immediate attention, such as trauma patients and critical care patients, especially in situations with limited staff.

Accurate preoperative diagnosis to clarify whether the appendix is perforated must be a prerequisite to delayed appendectomy. CT is a main diagnostic tool with high sensitivity and specificity for acute appendicitis. The routine use of CT in patients with suspected acute appendicitis has been shown to shorten the time to operating room admission, reduce the number of negative appendectomies, and reduce medical costs. ${ }^{15}$ Ultrasonography is another useful modality commonly used for children, pregnant patients, and outpatients, because it is noninvasive, does not require patient preparation, and avoids unnecessary exposure to ionizing radiation. Moreover, Peña et $a l^{16}$ demonstrated that an imaging protocol using US and CT was useful for distinguishing between nonperforated and perforated appendicitis, as shown by a marked decrease in the perforation and negative appendectomy rates in 1338 children with suspected appendicitis. However, this study showed that the false-positive rate of CT and US was as high as $53.9 \%(146 / 271)$ and $61.1 \%$ (58/95), respectively. As radiologic readings are not infallible, surgeons need to confirm the presence of perforation using symptoms, physical examinations, and laboratory findings. Radiologists must also pay close, critical attention to their radiologic interpretations.

At the beginning of this study, we predicted that there would be little difference in medical costs between the 2 groups because the additional hospitalization fees for the delayed group might be similar to the additional nighttime surgery fees for the immediate group. However, medical costs were significantly increased for the delayed group because the additional hospitalization fees were more expensive than the additional nighttime surgery fees in the immediate group. Surgeons should consider that increased medical costs can be a burden for patients and health insurance companies. In addition, the emotional and unanticipated economic cost of extended hospital stays in the delayed group should not be dismissed.

In conclusion, delayed appendectomy is safe for patients with acute nonperforated appendicitis. It can improve quality of provided care from surgeons, enhance quality of care for patients, and increase effective utilization of medical resources and operating rooms for life-threatening emergencies.

\section{Acknowledgments}

This work was supported by Kyung-Hee University Research Fund in 2008 (KHU-20081263).

\section{References}

1. Berry Jr J, Malt RA. Appendicitis near its centenary. Ann Surg 1984;200(5):567-575

2. Hansson J, Körner U, Khorram-Manesh A, Solberg A, Lundholm K. Randomized clinical trial of antibiotic therapy versus appendicectomy as primary treatment of acute appendicitis in unselected patients. Br J Surg 2009;96(5):473481

3. Styrud J, Eriksson S, Nilsson I, Ahlberg G, Haapaniemi S, Neovius $\mathrm{G}$ et al. Appendectomy versus antibiotic treatment in acute appendicitis. A prospective multicenter randomized controlled trial. World J Surg 2006;30(6):1033-1037

4. Ingraham AM, Cohen ME, Bilimoria KY, Ko CY, Hall BL, Russell TR et al. Effect of delay to operation on outcomes in adults with acute appendicitis. Arch Surg 2010;145(9):886-892

5. Abou-Nukta F, Bakhos C, Arroyo K, Koo Y, Martin J, Reinhold $\mathrm{R}$ et al. Effects of delaying appendectomy for acute appendicitis for 12 to 24 hours. Arch Surg 2006;141(5):504-506; discussion 506-507

6. Surana R, Quinn F, Puri P. Is it necessary to perform appendicectomy in the middle of the night in children? BMJ 1993;306(6886):1168

7. Yardeni D, Hirschl RB, Drongowski RA, Teitelbaum DH, Geiger JD, Coran AG. Delayed versus immediate surgery in acute appendicitis: do we need to operate during the night? J Pediatr Surg 2004;39(3):464-9; discussion 464-469 
8. Omundsen M, Dennett E. Delay to appendicectomy and associated morbidity: a retrospective review. ANZ J Surg 2006; 76(3):153-155

9. Ditillo MF, Dziura JD, Rabinovici R. Is it safe to delay appendectomy in adults with acute appendicitis? Ann Surg 2006;244(5):656-660

10. Udgiri N, Curras E, Kella VK, Nagpal K, Cosgrove J. Appendicitis, Is it an emergency? Am Surg 2011;77(7):898-901

11. Teixeira PG, Sivrikoz E, Inaba K, Talving P, Lam L, Demetriades D. Appendectomy timing: waiting until the next morning increases the risk of surgical site infections. Ann Surg 2012;256(3):538-543

12. Bufo AJ, Shah RS, Li MH, Cyr NA, Hollabaugh RS, Hixson SD et al. Interval appendectomy for perforated appendicitis in children. J Laparoendosc Adv Surg Tech A 1998;8(4):209-214
13. Weiner DJ, Katz A, Hirschl RB, Drongowski R, Coran AG. Interval appendectomy in perforated appendicitis. Pediatr Surg Int 1995;10(2-3):82-85

14. Mazziotti M, Marley E, Winthrop A, Fitzgerald P, Walton M, Langer J. Histopathologic analysis of interval appendectomy specimens: support for the role of interval appendectomy. $J$ Pediatr Surg 1997;32(6):806-809

15. Rao PM, Rhea JT, Novelline RA, Mostafavi AA, McCabe CJ. Effect of computed tomography of the appendix on treatment of patients and use of hospital resources. N Engl J Med 1998; 338(3):141-146

16. Peña BMG, Taylor GA, Fishman SJ, Mandl KD. Effect of an imaging protocol on clinical outcomes among pediatric patients with appendicitis. Pediatrics 2002;110(6):1088-1093 